\title{
Careers of non-medical graduates in British medical research
}

\author{
Judy Sadler, Ruth Porter \& David Evered*
}

THE major functions of a university department in a medical faculty are research, teaching and, in the case of clinical departments, patient care. It is not possible to quantify the relative importance of these various functions, but it is generally agreed that they are interdependent and that the creation of an environment in which these activities can thrive plays a major role in improving the quality of medical care. The contribution which the basic biological sciences have made to medical research has increased substantially in the past two decades - and increasing numbers of non-medical graduates are engaged in medical research both within and without medical faculties ${ }^{1,2}$. The importance of these contributions has been emphasized by various commentators ${ }^{3,4}$.

However, non-medical graduates in medical research and others have recently expressed their concern that no adequate career structure exists for those without a medical degree ${ }^{5-10}$. Career opportunities are available to this group of scientists in Medical Research Council institutes and units ${ }^{11}$, some privately funded research institutes and in non-clinical biomedical departments in the universities. But it has been argued that there are insufficient tenured posts to enable full-time research workers in the medical sciences to develop their ideas and skills to the full ${ }^{12,13}$. The controversy over the proper balance between short-term and long-term support for non-medical graduates in medical research has continued in the columns of many journals during the past three years. This debate has been taking place despite a remarkable lack of data on the distribution, nature of employment, qualifications, age, sex and sources of support of this group. This study was designed to remedy this deficiency and provide the necessary basic data for informed discussion.

\section{Survey method}

The study was designed to collect data on all non-medical scientists engaged in medical research in academic and nonprofit making institutions. A questionnaire was designed and validated in a pilot survey. The questionnaire in its definitive form was sent personally addressed to the head of each department or unit listed in the panel on the right with an explanatory letter. Reminders were sent 3 weeks and 6

*The Ciba Foundation, 41 Portland Place, L.ondon WIN 4BN, UK weeks after despatch of the original questionnaire to those failing to respond.

The questionnaire was designed to elicit the following information:

(1) Number of graduates engaged in medical research (medical and nonmedical graduates).

(2) The status of employment of non-medical scientists (permanent received from 798 university departments, $75 \mathrm{MRC}$ and other research institutes and units, 17 from Public Health Laboratory Service units, 12 from Blood Transfusion Service laboratories and 4 from other research units.

Medical research was carried out in 752 (83 per cent) of these departments and units and non-medical graduates were engaged

A survey to establish the numbers, status, professional qualifications and age of non-medical science graduates in medical research has been carried out by postal questionnaire. It shows that 31 per cent of all non-medical scientists hold permanent academic posts - but 56 per cent of those with a $P h D$ and 72 per cent of all those aged 35 or over have permanent positions; 42 per cent of non-medical scientists are purely grant supported. Amongst scientists dependent on shortterm grant support, 14.1 per cent had received support of this nature for 7 or more years and 4.7 per cent for 10 or more years.

academic, limited-tenur: academic, permanent technician, limited-term technician or short-term grant support only).

(3) Academic qualifications (that is, $\mathrm{PhD}$, other higher degree or first degree only) broken down by employment category.

(4) Ages (less than 25, 25-34, 35 or over) broken down by employment category.

(5) Duration of grant support for those with non-tenured positions.

(6) Sources of grant support.

The totals and numbers of males and females in each category were noted. All the data were also analysed by discipline of department, the nature of employing institutions and geographical area.

The survey was only concerned with non-medical graduates apart from the single question intended to identify the total number of medical graduates in research. Respondents were encouraged to record all non-medical graduates engaged in clinically orientated and basic biomedical research - either full-time or for the majority of their time. Graduates employed in an administrative support role were specifically excluded.

\section{Results}

A total of 1,146 questionnaires were sent out and 942 were returned ( 82 per cent) and of these 36 showed internal inconsistencies which made them unsuitable for analysis. The analysis, therefore, relates to the remaining 906 questionnaires ( 79 per cent of the original sample). Returns were in research in 680 departments and units (75 per cent of the total and 90 per cent of those engaged in research). A total of 2,855 medical graduates (of whom 2,458 ( 86 per cent) were male) and 7,950 non-medical graduates (of whom 5,155 (65 per cent) were male) were engaged in medical research. The male:female ratio for medical graduates was 6.2:1 and for nonmedical graduates 1.9:1.

The employment status of the nonmedical graduates in the study is shown in

\section{The survey population}

(1) All university departments in medical faculties in the United Kingdom.

(2) All university departments of biochemistry, biology, genetics, immunology, microbiology, psychology and zoology in science faculties in the United Kingdom.

(3) All Medical Research Council institutes and units.

(4) All institutes funded by medical research charities.

(5) Central Public Health Laboratories, reference and special laboratories and units, and regional and area laboratories.

(6) Regional Blood Transfusion Service centres. - The address and name of the head of each unit were taken from Medical Directory, 1979 (Churchill Livingstone, Edinburgh), Research in British Universities, Polytechnics and Colleges 1979/80 (British Library), European Research Index, 4th Edn 1977 (Francis Hodgson, Guernsey), MRC Handbook 1978/79, Handbook of British Medical Research Charities 1979, The Hospital and Health Service Year Book 1979 (Institute of Health Service Administrators), and Public Health Service Directory 1977 (London Public Health Laboratory Service). 
Table 1

\begin{tabular}{|c|c|c|c|c|c|c|c|}
\hline \multirow{2}{*}{$\begin{array}{l}\text { EMPLOYMENT } \\
\text { STATUS }\end{array}$} & \multicolumn{2}{|c|}{ MALE } & \multicolumn{2}{|c|}{ FEMALE } & \multicolumn{2}{|c|}{ ALL } & \multirow{2}{*}{$\begin{array}{l}\text { M:F } \\
\text { RATIO }\end{array}$} \\
\hline & Total & $\%$ & Total & $\%$ & Total & $\%$ & \\
\hline $\begin{array}{l}\text { Permanent } \\
\text { academic post }\end{array}$ & 2,009 & 39.0 & 423 & 15.2 & 2,432 & 30.6 & $4.7: 1$ \\
\hline L.imited-tenure & & & & & & & \\
\hline $\begin{array}{l}\text { academic post } \\
\text { Permanent }\end{array}$ & 717 & 13.9 & 410 & 14.7 & 1,127 & 14.2 & $1.7: 1$ \\
\hline $\begin{array}{l}\text { technician post } \\
\text { l.imited-term }\end{array}$ & 395 & 7.7 & 365 & 13.1 & 760 & 9.6 & $1.1: 1$ \\
\hline technician post & 125 & 2.4 & 194 & 7.0 & 319 & 4.0 & $0.6: 1$ \\
\hline Grant support & 1,909 & 37.0 & 1,393 & 50.0 & 3,302 & 41.6 & $1.4: 1$ \\
\hline
\end{tabular}

Table 1. It will be noted that 31 per cent have permanent academic posts $(\mathrm{M}: \mathrm{F}$ 4.7:1), a further 14 per cent have limitedtenure academic posts (M:F 1.7:1) and 42 per cent are purely grant supported $(\mathrm{M}: \mathrm{F}$ 1.4:1). A significant number of graduates (13.6 per cent of the total) are employed as technicians and over half of these are female. The population was further broken down with respect to their qualifications and these data are shown in Table 2 . Forty-five per cent of non-medical graduates in medical research have a $\mathrm{PhD}$ and the majority of these are male ( 53 per cent of the males compared with 28 per cent of females). Eighty per cent of those with a permanent academic post had a $\mathrm{PhD}$ (and a further 8 per cent some other higher degree) - and there was some difference between the sexes since 90 per cent of males but only 77 per cent of females with permanent positions had higher degrees. These differences, however, only partly reflect the fact that a much higher proportion of males hold a $\mathrm{PhD}$ and 62 per cent of the males but only 35 per cent of females with a PhD have a permanent post. Conversely, higher proportions of females with a $\mathrm{PhD}$ have limited-tenure academic posts ( 25 per cent) or are purely reliant upon grant support (37 per cent) by comparison with males holding a $\mathrm{PhD}$ (18 per cent and 19 per cent respectively). A very small number of graduates with a PhD are employed as technicians -56 in total of whom only 10 are in limited-term employment.

The population was analysed with respect to age (Table 3 ) and each subject was assigned to one of three age groups. The largest group (45 per cent of the total) was between the ages of 25 and 34 , and 29 over. The males were generally older than the females with 34 per cent being in the oldest age category and 23 per cent in the youngest - compared with 19 per cent and 32 per cent respectively for the females. Only 47 per cent of females aged 35 or over have permanent posts compared with 79 per cent of males - and conversely 31 per cent of females and only 10 per cent of males in the same age group are purely dependent upon grant support.

Analysis of the population by discipline revealed wide variations in the numbers of non-medical (and medical) graduates engaged in research (see Table 4) the largest number being in biochemistry and the smallest in radiology. Correction of these figures on a discipline by discipline basis indicates that there are 10,155 non-medical graduates engaged in medical research in the United Kingdom in the disciplines and institutions surveyed. The patterns of employment vary considerably from discipline to discipline. Permanent posts are held by 50 per cent or more of the nonmedical graduates in occupational medicine ( 76 per cent), medical physics ( 56 per cent) and otorhinolaryngology (50 per cent) - and by 40 per cent of the nonmedical graduates in anatomy, haematology and forensic medicine. At the other end of the scale permanent posts are available for less than 10 per cent of the per cent of the population was aged 35 and

Table 2 Qualifications by status of employment (\% in each employment category)

\begin{tabular}{|c|c|c|c|c|c|c|c|c|c|}
\hline & & MALES & & & FEMALE & & & ALL & \\
\hline $\begin{array}{l}\text { Permanent } \\
\text { academic post }\end{array}$ & $\begin{array}{c}\text { PhD } \\
1,681 \\
(83.2 \%)\end{array}$ & $\begin{array}{c}\text { Other } \\
\text { higher } \\
\text { degree } \\
148 \\
(7.3 \%)\end{array}$ & $\begin{array}{c}\text { First } \\
\text { degree } \\
\text { only } \\
191 \\
(9.5 \%)\end{array}$ & $\begin{array}{c}\mathrm{PhD} \\
277 \\
(65.3 \%)\end{array}$ & $\begin{array}{c}\text { Other } \\
\text { higher } \\
\text { degree } \\
50 \\
(11.8 \%)\end{array}$ & $\begin{array}{c}\text { First } \\
\text { degree } \\
\text { only } \\
97 \\
(22,90 \%)\end{array}$ & $\begin{array}{c}\text { PhD } \\
1,958 \\
(80.1 \%)\end{array}$ & $\begin{array}{c}\text { ()her } \\
\text { higher } \\
\text { degree } \\
198 \\
(8.1 \%)\end{array}$ & $\begin{array}{c}\text { First } \\
\text { degree } \\
\text { only } \\
288 \\
(11.800)\end{array}$ \\
\hline $\begin{array}{l}\text { Limited-tenure } \\
\text { academic post }\end{array}$ & $\begin{array}{c}483 \\
(67,9 \%)\end{array}$ & $\begin{array}{c}69 \\
(9.7 \%)\end{array}$ & $\begin{array}{c}159 \\
(22.4 \%)\end{array}$ & $\begin{array}{c}199 \\
(47.7 \%)\end{array}$ & $\begin{array}{c}62 \\
(14.9 \%)\end{array}$ & $\begin{array}{c}156 \\
(37.4 \%)\end{array}$ & $\begin{array}{c}682 \\
(60.5 \%)\end{array}$ & $\begin{array}{c}131 \\
(11.6 \%)\end{array}$ & $\begin{array}{c}315 \\
(28.90 \%)\end{array}$ \\
\hline $\begin{array}{l}\text { Permanent } \\
\text { technician post }\end{array}$ & $\begin{array}{c}30 \\
(7.6 \%)\end{array}$ & $\begin{array}{c}63 \\
(16.0 \%)\end{array}$ & $\begin{array}{c}301 \\
(76.4 \%)\end{array}$ & $\begin{array}{c}16 \\
(4.4 \%)\end{array}$ & $\begin{array}{c}42 \\
(11.5 \%)\end{array}$ & $\begin{array}{c}307 \\
(84.1 \%)\end{array}$ & $\begin{array}{c}46 \\
(6.1 \%)\end{array}$ & $\begin{array}{c}105 \\
(13.8 \%)\end{array}$ & $\begin{array}{c}608 \\
(80.1 \%)\end{array}$ \\
\hline $\begin{array}{l}\text { 1.imited-term } \\
\text { technician post }\end{array}$ & $\begin{array}{c}5 \\
(4.0 \%)\end{array}$ & $\begin{array}{c}11 \\
(8.8 \%)\end{array}$ & $\begin{array}{c}109 \\
(87.2 \%)\end{array}$ & $\begin{array}{c}5 \\
(2.6 \%)\end{array}$ & $\begin{array}{c}9 \\
(4.7 \%)\end{array}$ & $\begin{array}{c}178 \\
(92.7 \%)\end{array}$ & $\begin{array}{c}10 \\
(3.2 \%)\end{array}$ & $\begin{array}{c}20 \\
(6.3 \%)\end{array}$ & $\begin{array}{c}287 \\
(90.50 \%)\end{array}$ \\
\hline Girant support & $\begin{array}{c}515 \\
(28.0 \%)\end{array}$ & $\begin{array}{c}210 \\
(11.4 \%)\end{array}$ & $\begin{array}{c}1,116 \\
(60.6 \%)\end{array}$ & $\begin{array}{c}293 \\
(21.2 \%)\end{array}$ & $\begin{array}{c}157 \\
(11.4 \%)\end{array}$ & $\begin{array}{c}929 \\
(67.4 \%)\end{array}$ & $\begin{array}{c}808 \\
(25.1 \%)\end{array}$ & $\begin{array}{c}367 \\
(11.4 \% 0)\end{array}$ & $\begin{array}{c}2,045 \\
(63.5 \%)\end{array}$ \\
\hline TOTAISS & $\begin{array}{c}2,714 \\
(53.4 \%)\end{array}$ & $\begin{array}{c}501 \\
(9.8 \%)\end{array}$ & $\begin{array}{c}1,876 \\
(36.8 \% 0)\end{array}$ & $\begin{array}{c}790 \\
(28.4 \%)\end{array}$ & $\begin{array}{c}320 \\
(11.5 \%)\end{array}$ & $\begin{array}{c}1,667 \\
(60.1 \%)\end{array}$ & $\begin{array}{c}3,504 \\
(44.5 \%)\end{array}$ & $\begin{array}{c}821 \\
(10.4 \%)\end{array}$ & $\begin{array}{c}3,543 \\
(45.1 \% 0)\end{array}$ \\
\hline
\end{tabular}

non-medical graduates in research in radiology, venereology and geriatric medicine - it must be added that the total number of non-medical graduates in these disciplines is very small. It was noted that four disciplines relied on grant support for more than 60 per cent of their non-medical graduates (neurology and neurosurgery, dermatology, immunology, and cardiothoracic medicine and surgery) and that four disciplines had a large proportion of non-medical graduates in technician posts (radiology 50 per cent, venereology 46 per cent, medicine 33 per cent and surgery 30 per cent).

The frequency of different qualifications also varied widely between disciplines. Fifty per cent or more of the science graduates in radiotherapy, pathology, physiology, medical physics, anatomy and biochemistry held a PhD. A large proportion of graduates with a first degree only were seen in radiology ( 83 per cent), general practice (75 per cent), geriatric medicine (65 per cent), cardiothoracic medicine and surgery (63 per cent) and venereology (62 per cent). Some differences in age distribution were seen between disciplines with a relatively high proportion of non-medical graduates aged 35 or over in radiology, radiotherapy, child health and infectious diseases and tropical medicine.

\section{Institution type}

The survey results were also analysed with respect to the nature of the employing institution. The research institutes and university departments had similar proportions of their staff in permanent academic posts. The institutes also supported a relatively large number of limited-tenure established posts and were considerably less dependent upon shortterm grant support than university departments. The Public Health and Blood Transfusion Laboratories had a high proportion of permanent posts reflecting their heavy service commitments. There were no major differences between the types of organization with respect to the qualification of the non-medical graduates although a slightly higher proportion of those employed in research institutes or units had a PhD or other higher qualification than did those in the university population and the lowest proportion with a higher qualification was seen in public health laboratories and blood transfusion services. The age distribution in the different organizations was similar.

\section{Grant support}

The study was extended with respect to those graduates dependent upon grant support. The survey identified 4,748 nonmedical graduates with limited-tenure employment and data on the duration and nature of grant support were available for 4,155 ( 88 per cent) of this group (a proportion of the remainder held posts of limited-tenure which were not dependent 
upon short-term grant support). The duration of grant support for these graduates is shown in Table 5 . The duration of grant support is similar for both sexes - 86 per cent of males and females have been receiving grant support for less than 6 years and 14 per cent for 7 years or more. The source of the present grant was the MRC for 34 per cent of these graduates, other research councils for 12 per cent, health service funds for 9 per cent, medical research charities for 21 per cent and other sources for 24 per cent. The latter category included overseas sources, pharmaceutical companies and government departments other than the Department of Health and Social Security and the Scottish Home and Health Department.

\section{Discussion}

The survey was carried out in the spring and early summer of 1980 and provides data on the numbers, distribution and characteristics of graduates engaged largely or wholly in medically orientated research at that time. It is purely a crosssectional survey and thus suffers from the inherent disadvantages of all prevalence studies. The particular advantages of this survey are that a whole population was surveyed (rather than just a sample) and the response rate was high for a postal survey. It is clear that non-medical scientists constitute a substantial proportion (74 per cent) of this population - and that there are probably approximately 10,000 nonmedical scientists in research in the United Kingdom in the institutions surveyed. This latter figure allows for the non-responders and is likely to be of the right order of magnitude since the response rate of those disciplines with large numbers of graduates in research was very similar to those disciplines with only a minor commitment to research. It is clear that this survey underestimates the total number of graduates in biomedical research since it does not include those in industry (particularly the pharmaceutical industry and those companies with an interest in biotechnology) and it also excluded research workers in some other university departments or research institutes (for example in the agricultural sciences) whose basic biological work may have particular relevance for the medical sciences. This study also does not include those scientists who are primarily employed to provide laboratory services, who may make occasional, but important, contributions to the pool of medical knowledge.

\section{Sex difference}

The employment status of the non-medical scientists was examined in detail, and related to their age and qualifications. There were some differences between the sexes in that a larger proportion of males had a higher degree and they were in general older than the females engaged in research. Even when these factors were

Table 3 Age distribution by status of employment ( $\%$ in each employment category)

\begin{tabular}{|c|c|c|c|c|c|c|c|c|c|}
\hline \multirow[b]{3}{*}{$\begin{array}{l}\text { Permanent } \\
\text { academic post }\end{array}$} & \multicolumn{3}{|c|}{ MALES } & \multicolumn{3}{|c|}{ FEMALES } & \multicolumn{3}{|c|}{ ALL } \\
\hline & $<25$ & $25-34$ & $35+$ & $<25$ & $25-34$ & $35+$ & $<25$ & $25-34$ & $35+$ \\
\hline & $\begin{array}{c}38 \\
(1.9 \%)\end{array}$ & $\begin{array}{c}600 \\
(30.0 \%)\end{array}$ & $\begin{array}{c}1,365 \\
(68.1 \%)\end{array}$ & $\begin{array}{c}17 \\
(4.0 \%)\end{array}$ & $\begin{array}{c}154 \\
(36.5 \%)\end{array}$ & $\begin{array}{c}251 \\
(59.5 \%)\end{array}$ & $\begin{array}{c}55 \\
(2.3 \%)\end{array}$ & $\begin{array}{c}754 \\
(31.1 \%)\end{array}$ & $\begin{array}{c}1,616 \\
(66.6 \%)\end{array}$ \\
\hline $\begin{array}{l}\text { Limited-tenure } \\
\text { academic post }\end{array}$ & $\begin{array}{c}104 \\
(14.6 \%)\end{array}$ & $\begin{array}{c}512 \\
(72.1 \%)\end{array}$ & $\begin{array}{c}94 \\
(13.3 \%)\end{array}$ & $\begin{array}{c}98 \\
(24.2 \%)\end{array}$ & $\begin{array}{c}246 \\
(60.7 \%)\end{array}$ & $\begin{array}{c}61 \\
(15.1 \%)\end{array}$ & $\begin{array}{c}202 \\
(18.1 \%)\end{array}$ & $\begin{array}{c}758 \\
(68.0 \%)\end{array}$ & $\begin{array}{c}155 \\
(13.9 \%)\end{array}$ \\
\hline $\begin{array}{l}\text { Permanent } \\
\text { technician post }\end{array}$ & $\begin{array}{c}89 \\
(22.7 \%)\end{array}$ & $\begin{array}{c}218 \\
(55.6 \%)\end{array}$ & $\begin{array}{c}85 \\
(21.7 \%)\end{array}$ & $\begin{array}{c}94 \\
(25.8 \%)\end{array}$ & $\begin{array}{c}228 \\
(62.6 \%)\end{array}$ & $\begin{array}{c}42 \\
(11.6 \%)\end{array}$ & $\begin{array}{c}183 \\
(24.2 \%)\end{array}$ & $\begin{array}{c}446 \\
(59.0 \%)\end{array}$ & $\begin{array}{c}127 \\
(16.8 \%)\end{array}$ \\
\hline $\begin{array}{l}\text { Limited-term } \\
\text { technician post }\end{array}$ & $\begin{array}{c}58 \\
(46.4 \%)\end{array}$ & $\begin{array}{c}56 \\
(44.8 \%)\end{array}$ & $\begin{array}{c}11 \\
(8.8 \%)\end{array}$ & $\begin{array}{c}82 \\
(43.9 \%)\end{array}$ & $\begin{array}{c}91 \\
(48.7 \%)\end{array}$ & $\begin{array}{c}14 \\
(7.4 \%)\end{array}$ & $\begin{array}{c}140 \\
(44.9 \%)\end{array}$ & $\begin{array}{c}147 \\
(47.1 \%)\end{array}$ & $\begin{array}{c}25 \\
(8.0 \%)\end{array}$ \\
\hline Grant support & $\begin{array}{c}871 \\
(46.2 \%)\end{array}$ & $\begin{array}{c}844 \\
(44.8 \%)\end{array}$ & $\begin{array}{c}170 \\
(9.0 \%)\end{array}$ & $\begin{array}{c}588 \\
(42.7 \%)\end{array}$ & $\begin{array}{c}623 \\
(45.2 \%)\end{array}$ & $\begin{array}{c}166 \\
(12.1 \%)\end{array}$ & $\begin{array}{c}1,459 \\
(44.7 \%)\end{array}$ & $\begin{array}{c}1,467 \\
(45.00 \%)\end{array}$ & $\begin{array}{c}336 \\
(10.3 \%)\end{array}$ \\
\hline TOTALS & $\begin{array}{c}1,160 \\
(22.7 \%)\end{array}$ & $\begin{array}{c}2,230 \\
(43.6 \%)\end{array}$ & $\begin{array}{c}1,725 \\
(33.7 \%)\end{array}$ & $\begin{array}{c}879 \\
(31.9 \%)\end{array}$ & $\begin{array}{c}1,342 \\
(48.7 \%)\end{array}$ & $\begin{array}{c}534 \\
(19.4 \%)\end{array}$ & $\begin{array}{c}2,039 \\
(25.9 \%)\end{array}$ & $\begin{array}{c}3,572 \\
(45.4 \%)\end{array}$ & $\begin{array}{c}2,259 \\
(28.7 \% 0)\end{array}$ \\
\hline
\end{tabular}

Table 4 Distribution of non-medical and medical graduates by discipline

Discipline

Anaesthetics

Anatomy

Biochemistry

Biology

Cancer (oncology) (1)

Cardio-thoracic medicine \& surgery

Chemical pathology (2)

Child health

Community medicine

Dermatology

Forensic medicine

General practice

Genetics

Geriatric medicine

Haematology (3)

Immunology

Infectious diseases \& tropical medicine

Medical physics

Medicine (4)

Mental health \& psychiatry

Microbiology (5)

Miscellaneous (6)

Neurology \& neurosurgery

Obstetrics \& gynaecology

Occupational medicine

Ophthalmology

Orthopaedics

Otorhinolaryngology

Pathology

Physiology

Pharmacology

Psychology

Radiology

Radiotherapy

Surgery (7)

Therapeutics \& clinical pharmacology

Venereology

Zoology

No. of
institution
responding
19
25
49
36
9
10
26
21
31
17
10
12
18
8
25
5
15
9
49
30
60
35
19
28
25
19
15
14
44
34
28
41
18
16
40
19
12
33

\begin{tabular}{|c|c|c|c|}
\hline \multicolumn{2}{|c|}{$\begin{array}{l}\text { Non-medical } \\
\text { graduates }\end{array}$} & \multicolumn{2}{|c|}{$\begin{array}{l}\text { Medical } \\
\text { graduates }\end{array}$} \\
\hline No. & Mean & No. & Mean \\
\hline 30 & 1.6 & 66 & 3.5 \\
\hline 207 & 8.3 & 132 & 5.3 \\
\hline 1,130 & 38.3 & 28 & 0.7 \\
\hline 485 & 13.5 & 15 & 0.4 \\
\hline 17 & 1.9 & 22 & 2.4 \\
\hline 45 & 4.5 & 51 & 5.1 \\
\hline 407 & 15.7 & 104 & 4.0 \\
\hline 55 & 2.6 & 98 & 4.7 \\
\hline 187 & 6.0 & 121 & 3.9 \\
\hline 51 & 3.0 & 50 & 2.9 \\
\hline 15 & 1.5 & 8 & 0.8 \\
\hline 8 & 0.7 & 25 & 2.1 \\
\hline 218 & 12.1 & 23 & 1.3 \\
\hline 17 & 2.1 & 14 & 1.8 \\
\hline 114 & 4.6 & 71 & 2.8 \\
\hline 84 & 16.8 & 26 & 5.2 \\
\hline 104 & 6.9 & 28 & 1.9 \\
\hline 346 & 18.2 & 19 & 1.0 \\
\hline 560 & 11.4 & 467 & 9.5 \\
\hline 398 & 13.3 & 124 & 4.1 \\
\hline 399 & 6.6 & 130 & 2.2 \\
\hline 192 & 5.5 & 24 & 0.7 \\
\hline 38 & 2.0 & 53 & 2.8 \\
\hline 121 & 4.3 & 133 & 4.8 \\
\hline 90 & 3.6 & 13 & 0.5 \\
\hline 43 & 2.3 & 50 & 2.6 \\
\hline 49 & 3.3 & 49 & 3.3 \\
\hline 20 & 1.4 & 21 & 1.5 \\
\hline 529 & 12.0 & 222 & 5.0 \\
\hline 704 & 20.7 & 180 & 5.3 \\
\hline 482 & 17.2 & 63 & 2.3 \\
\hline 192 & 4.7 & 7 & 0.2 \\
\hline 6 & 0.3 & 37 & 2.1 \\
\hline 97 & 6.1 & 29 & 1.8 \\
\hline 136 & 3.4 & 210 & 5.3 \\
\hline 191 & 10.1 & 99 & 5.2 \\
\hline 13 & 1.1 & 35 & 2.9 \\
\hline 275 & 8.3 & 8 & 0.2 \\
\hline
\end{tabular}

(1) Cancer research is also included in biology, pathology and radiotherapy.

(2) Includes clinical biochemistry, clinical chemistry and metabolism.

(3) Includes blood transfusion.

(4) Includes all medical specialties not classified separately.

(5) Includes bacteriology and virology.

(6) Includes statistics, biomedical engineering, medicinal chemistry, etc.

(7) Includes all surgical specialities not classified separately.

taken into account, male graduates were more likely to obtain a permanent position. There are several possible explanations for these differences and this survey cannot with certainty distinguish between these possibilities. However, precisely the same proportion of females and males who were dependent upon grant support had been recipients of grants for seven years or more, suggesting that the difference overall is due to the fact that a proportion of females leave medical research but return after a few years.

\section{Disciplines}

There were some very considerable differences between the various disciplines. A very weak (and statistically not 
significant) positive relationship was noted between the mean number of non-medical scientists in each discipline and the proportion who held permanent academic positions. Generally, the more highly qualified non-medical graduates and the highest proportion with permanent posts, were to be found in the sciences basic to medicine and in those disciplines which commonly carried a substantial service laboratory load in addition to their academic commitments. This impression was confirmed by the high proportion of permanent staff in the Public Health Laboratory Service and the Blood Transfusion Service. The purely clinical disciplines and particularly the 'minor' medical specialties generally had the smallest commitment to medical research, the lowest numbers of medical and nonmedical graduates engaged in research and very few permanent posts.

\section{Scope}

Several general points should be made in relation to this survey. First, it must be recognized that this pool of non-medical scientists is in equilibrium with other populations of biological scientists in universities, industry, other institutes, government and the schools - some of whom will be occupied in research while others will be undertaking other functions

\section{The reasons why}

BEHIND both the accompanying study and the recent report commissioned by the US National Science Foundation (see above and also Nature 11 June) lies a good deal of unrest amongst junior research scientists. The US report, carried out by the National Academy of Sciences (National Research Council) with a steering committee chaired by $\mathrm{Dr}$ Lee Grodzins of the Massachussetts Institute of Science and Technology, gives expression to some of the discontent shown by postdoctorals in the United States and lists amongst its conclusions: -We have found a lack of concern on the part of most universities for the well being of their postdoctorals as an identifiable group.

- Few universities assume any responsibility for shaping or even monitoring the character of the postdoctoral experience or for ensuring its quality.

-A significant fraction - in some fields the majority - of postdoctorals deplore many of the conditions of their appointments.

- Postdoctoral experience contributes little or nothing in terms of subsequent income.

-Women postdoctorals are more likely than their male counterparts to pursue academic careers, but the men entering academic employment are more likely to get faculty appointments and are more

Table 5

Duration of grant support to 4,155 non-medical graduates

\begin{tabular}{lrrrrrr}
\hline DURATION OF SUPPORT & \multicolumn{2}{c}{ MALES } & \multicolumn{2}{c}{ FEMALES } & \multicolumn{2}{c}{ ALL } \\
Less than 3 years & 961 & $(40.2 \%)$ & 808 & $(45.8 \%)$ & 1,769 & $(42.6 \%)$ \\
3-6 years & 1,092 & $(45.6 \%)$ & 707 & $(40.1 \%)$ & 1,798 & $(43.3 \%)$ \\
$7-10$ years & 231 & $(9.7 \%)$ & 159 & $(9.0 \%)$ & 390 & $(9.4 \%)$ \\
More than 10 years & 109 & $(4.5 \%)$ & 89 & $(5.1 \%)$ & 198 & $(4.7 \%)$ \\
\hline
\end{tabular}

(teaching, administration, technical services and so on). The appropriate relative proportions of these various scientific populations will always be debatable - but it is essential to remember that the career opportunities available to the graduate in the biological sciences are not limited to the institutions which were the subject of this survey. Second, it must be emphasized that this survey does no more than describe a population and its characteristics. There are no available methods for determining the 'ideal' balance between long-term and short-term support, or indeed for establishing the optimum level of investment in biomedical research. The controversy relating to the status, career structure and mechanisms of funding of non-medical scientists in medical research will undoubtedly continue. The major objective of this survey was to provide information, which hitherto has been lacking, as the basis for

quickly given tenure.

The supply of secure, tenured academic posts no longer matches the numbers of postdoctoral researchers that are required to keep the 'academic research industry' going (if ever it did) and so there will always be a steady stream of postdoctorals failing to find a niche in academia. The US report recommends that individual universities should set up standing committees to review the conditions of postdoctorals, with emphasis on salary (or stipend) levels, status within the university community, availability of career counselling, and subsequent employment of those completing appointments.

The National Science Foundation already sponsors data collection in the fields of research funding, graduate enrolments, doctoral awards, and science and engineering employment. The report calls for the foundation to introduce surveys on the career decisions of young scientists and engineers and to publish a bienniel series of reports on the changing patterns and utilization of postdoctorals and other groups of young investigators. Armed with such information the requested standing committees may be in a position to give some useful advice.

Despite the difficulties though, the report concludes that postdoctoral fellowships make an invaluable contribution to research, and remain a valuable preparation for academic iife. $\square$ this debate. The importance of providing this database is underlined by the observation that approximately 10,000 non-medical scientists are engaged in research in the institutions surveyed.

\section{US study}

Recently published data ${ }^{14}$ from the United States provide a valuable comparison with the present observations, suggesting that there are approximately 7,000 postdoctoral fellows in the United States without permanent posts, compared with about 1,750 in the United Kingdom identified by the present survey. The two are not directly comparable but even so, closely reflect the ratio of the total and graduate populations in the two countries. The US study contains some longitudinal observations and indicates that the input to the "post doctoral holding pattern" exceeds the output to tenured positions by 11 per cent. The authors of this report highlight the problem of balancing the needs of the individual scientist against the long-term research requirements of the community. It is clear from our survey and from the US study that long-term policies of support for biomedical research should be based upon objective observations of personnel and performance.

We thank Professor A. G. Shaper and members of the Department of Clinical Epidemiology and Social Medicine, Royal Free Hospital, London, particularly Dr S. J. Pocock and Miss L. M. Carpenter, for statistical advice and help in designing the pilot study and questionnaire, and Brigadier K. David Gribbin (SecretaryGeneral of the Cancer Research Campaign) for his comments. We also thank the many heads of departments and institutes who spent a great deal of time filling in the five-page questionnaire.

1. Coggeshall, P.E., Norvell, J.C., Bogorad, I.. \& Bock, R.M. Science 202, 487-493 (1978)

2. Gillis, C.N. Fedn Proc. 38, 2355-2358 (1979).

3. Comroe, J.H.\& Dripps, R.D. Science 192, 105-111 (1976).

4. Perutz, M.F. Ciba Fdn Symp. N.S. 44, 115-135 (1976).

5. The Case for Careers in Medical Research 1-21 (Association of Researchers in Medical Sciences, 1.ondon, 1980).

6. Schwartz, J, Nature 276, 310-311 (1978)

7. Lancet i, 912-913 (1979).

8. Schwartz, J. Nature 276, 745 (1978).

9. Schwartz, J. Nature 282, 7-8 (1979).

10. Dalyell, T. New Scient. 84, 213 (1979).

11. Redfearn, J. Nature 282, 8 (1979).

12. Hemming, F.W. Biochem. Soc. Bull. 1, 7-8(1979).

13. Simmonds, A. \& Unger, A. Trends biochem. Sci. 5 , 10-11 (1980).

14. Postdoctoral Appointments and Disappointments (National Research Council, National Academy Press, Washington DC, 1981). 